\title{
The PDE4 inhibitor roflumilast improves memory in rodents at non-emetic doses
}

Citation for published version (APA):

Vanmierlo, T., Creemers, P., Akkerman, S., van Duinen, M., Sambeth, A., De Vry, J., Uz, T., Blokland, A., \& Prickaerts, J. (2016). The PDE4 inhibitor roflumilast improves memory in rodents at non-emetic doses. Behavioural Brain Research, 303, 26-33. https://doi.org/10.1016/j.bbr.2016.01.031

Document status and date:

Published: 15/04/2016

DOI:

10.1016/j.bbr.2016.01.031

Document Version:

Publisher's PDF, also known as Version of record

Document license:

Taverne

Please check the document version of this publication:

- A submitted manuscript is the version of the article upon submission and before peer-review. There can be important differences between the submitted version and the official published version of record.

People interested in the research are advised to contact the author for the final version of the publication, or visit the DOI to the publisher's website.

- The final author version and the galley proof are versions of the publication after peer review.

- The final published version features the final layout of the paper including the volume, issue and page numbers.

Link to publication

\footnotetext{
General rights Owners
rights.

- You may freely distribute the URL identifying the publication in the public portal. please follow below link for the End User Agreement:

www.umlib.nl/taverne-license

Take down policy

If you believe that this document breaches copyright please contact us at:

repository@maastrichtuniversity.nl

providing details and we will investigate your claim.
}

Copyright and moral rights for the publications made accessible in the public portal are retained by the authors and/or other copyright owners and it is a condition of accessing publications that users recognise and abide by the legal requirements associated with these

- Users may download and print one copy of any publication from the public portal for the purpose of private study or research.

- You may not further distribute the material or use it for any profit-making activity or commercial gain

If the publication is distributed under the terms of Article $25 \mathrm{fa}$ of the Dutch Copyright Act, indicated by the "Taverne" license above, 


\title{
The PDE4 inhibitor roflumilast improves memory in rodents at non-emetic doses
}

\author{
Tim Vanmierlo ${ }^{a, b}$, Pim Creemers ${ }^{a, 1}$, Sven Akkerman ${ }^{a}$, Marlies van Duinen ${ }^{a}$, \\ Anke Sambeth ${ }^{\mathrm{c}}$, Jochen De Vry ${ }^{\mathrm{a}}$, Tolga Uz ${ }^{\mathrm{d}}$, Arjan Blokland ${ }^{\mathrm{c}}$, Jos Prickaerts ${ }^{\mathrm{a}, *}$ \\ ${ }^{a}$ Dept. of Psychiatry and Neuropsychology, School for Mental Health and Neuroscience, Maastricht University, Maastricht, the Netherlands \\ ${ }^{\mathrm{b}}$ Dept. of Immunology and Biochemistry, BIOMED, Hasselt University, Hasselt, Belgium \\ ${ }^{c}$ Dept. of Neuropsychology and Psychopharmacology, Maastricht University, Maastricht, the Netherlands \\ d Experimental Medicine CNS, Takeda Development Center Americas, Inc., Deerfield, USA
}

\section{H I G H L I G H T S}

- Roflumilast improves spatial memory equal to rolipram in rodents.

- Roflumilast treatment evokes less emetic side effects compared to rolipram.

- Combining sub-efficacious doses of roflumilast and donepezil is fully effective in improving spatial memory.

\section{A R T I C L E I N F O}

\section{Article history:}

Received 22 December 2015

Received in revised form 10 January 2016

Accepted 13 January 2016

Available online 18 January 2016

\section{Keywords:}

PDE4

PDE4 inhibition

Roflumilast

Rolipram

Cognition

Memory

Emesis

cAMP

\begin{abstract}
A B S T R A C T
Enhancement of central availability of the second messenger cAMP is a promising approach to improve cognitive function. Pharmacological inhibition of phosphodiesterase type 4 (PDE4), a group of cAMP hydrolyzing enzymes in the brain, has been shown to improve cognitive performances in rodents and monkeys. However, inhibition of PDE4 is generally associated with severe emetic side-effects. Roflumilast, an FDA-approved PDE4 inhibitor for treatment of chronic obstructive pulmonary disease (COPD), is yielding only mild emetic side effects.

In the present study we investigate the potential of roflumilast as a cognition enhancer and to determine the potential coinciding emetic response in comparison to rolipram, a classic PDE4 inhibitor with pronounced emetic effects.

Cognition enhancement was evaluated in mice and it was found that both roflumilast and rolipram enhanced memory in an object location task $(0.03 \mathrm{mg} / \mathrm{kg})$, whereas only roflumilast was effective in a spatial Y-maze $(0.1 \mathrm{mg} / \mathrm{kg})$. Emetic potential was measured using competition of PDE4 inhibition for $\alpha 2$-adrenergic receptor antagonism in which recovery from xylazine/ketamine-mediated anesthesia is used as a surrogate marker. While rolipram displayed emetic properties at a dose 10 times the memory-enhancing dose, roflumilast only showed increased emetic-like properties at a dose 100 times the memory-enhancing dose. Moreover, combining sub-efficacious doses of the approved cognitionenhancer donepezil and roflumilast, which did not improve memory when given alone, fully restored object recognition memory deficit in rats induced by the muscarinic receptor antagonist scopolamine. These findings suggest that roflumilast offers a more favorable window for treatment of cognitive deficits compared to rolipram.
\end{abstract}

(C) 2016 Elsevier B.V. All rights reserved.

\footnotetext{
* Corresponding author at: Dept. Psychiatry and Neuropsychology, School of Mental Health and Neuroscience, Maastricht University, P.O. Box 616, 6200 MD Maastricht, the Netherlands. Fax: +31 433884086.

E-mail address: jos.prickaerts@maastrichtuniversity.nl (J. Prickaerts).

1 Dept. of Neuromodulation, Clinical, Boston Scientific Group Plc., Maastricht, the Netherlands.
}

\section{Introduction}

Phosphodiesterase type 4 inhibitors (PDE4-Is) are a group of drugs that prevent hydrolyzing of the intracellular second messenger cyclic adenosine monophosphate (cAMP), thereby prolonging the cAMP-induced downstream signaling [1]. cAMP activates protein kinase $A$ (PKA), resulting in the phosphorylation of the 
transcription factor cAMP response element binding protein ( $\mathrm{P}$ CREB). P-CREB induces expression of CREB responsive genes involved in a wide range of biological functions, such as synaptic plasticity, memory and cognition [2-6], but also inflammation and bronchodilation [7-11].

PDE4 is expressed in the hippocampus and cortex [12,13] and was also found to remain present in the aged and Alzheimer brain $[14,15]$. It can therefore be considered as a promising target for enhancement of cognitive functions. Acute treatment with a PDE4-I clearly improved cognitive functions in healthy and pharmacologically impaired rodents which was particularly investigated using the classic PDE4-I rolipram (e.g., Refs. [3,16]; for reviews see Refs. [17-19]). Chronic treatment with rolipram is also beneficial for brain plasticity and cognitive function as was found in age-impaired mice and transgenic mice models of Alzheimer's disease (e.g., Refs. [20,21]; for reviews see Refs. [17,18]). Moreover, acute treatment with rolipram [22] or the PDE4-I D159687 [23] improved cognition including executive function/planning in monkeys. In humans, only a few PDE4-Is have been tested up to clinical phase II studies. For instance, MK-0952 was tested on cognitive impairment in mild to moderate Alzheimer's disease (ClinicalTrials.gov, NCT00362014). However, its announced results [24] have not been disclosed. Currently, HT-0712 is being tested on age-associated memory impairment (ClinicalTrials.gov, NCT02013310).

The development of PDE4-Is as therapeutic drugs has been hampered by the dose-limiting emetic side effects (nausea and even vomiting) in humans [25-27], as was particularly evident with rolipram. Whether MK-0952 and HT-0712 have emetic effects is not yet known. Currently, PDE4-Is are being developed that show a strong reduction in emetic side effects. Roflumilast is such an example and its effect on nausea is mostly mild or moderate in intensity and occurs in only 5\% of the subjects [28]. In 2011 the selective PDE4-I roflumilast was approved by the FDA as an antiinflammatory drug under the name of Daliresp or Daxas, indicated as a treatment to reduce the risk of chronic obstructive pulmonary disease (COPD) exacerbations in patients with severe COPD associated with chronic bronchitis and a history of exacerbations [29,30].

PDE4 is a family of proteins encoded by four different genes (PDE4A-D). In addition, each gene has multiple splice variants (e.g., PDE4D1-PDE4D11) [19]. Rolipram and roflumilast show no PDE4 subtype selectivity, with the exception of PDE4C, which is inhibited at a slightly lower potency [31]. It has been demonstrated that PDE4D splice variants are a very selective target for memory enhancement $[5,10]$. Therefore, PDE4-Is and in particular selective PDE4D-Is provide a promising target for cognition enhancement. However, in particular PDE4D inhibition has been attributed to induce emesis [32,33]. This is likely due to inhibition of PDE4D in the area postrema and nucleus of the solitary tract, which are responsible for the emetic reflex, as well as in the gut. Thus, it remains a challenge to reduce the emetic effect of possible PDE4-Is that enhance cognition. One approach to achieve this is by designing small-molecule negative allosteric modulators of PDE4D, e.g., D159687, that do not completely inhibit enzymatic activity (Imax 80-90\%) [10,34]. Another approach is to design selective full (Imax 100\%) PDE4D inhibitors, such as Gebr7b, that nevertheless show a partial reduction in emetic potential [35] (and recently reviewed in Ref. [36]).

Because of the reduced emetic properties of roflumilast in humans we explored in the present preclinical study whether roflumilast has the potential to test as a translational cognition enhancer (e.g., ClinicalTrials.gov, NCT01433666). First we determined whether roflumilast improves memory in mice, using the object location test (OLT) and the spatial Y-maze, which are based on the natural tendency of rodents to explore displaced objects and novel spatial environment [37,38]. As rodents are unable to vomit, we investigated the emetic properties using the xylazine/ketamine-induced anesthesia test. PDE4-Is mimic the pharmacological actions of $\alpha 2$-adrenoceptor antagonists, which has been described as the mechanism by which in particular PDE4D-Is induce emesis [32,33]. Since $\alpha 2$-adrenoceptor antagonists are also known to reverse xylazine/ketamine-induced anesthesia, the latter effect can be used as a surrogate measure of emesis in rodents [32,33]. Next, the mice were used for a pharmacokinetic study to verify central availability and biological activity of the PDE4-Is. Finally, we tested the potential beneficial interaction between the acetylcholinesterase inhibitor (AChE-I) donepezil, which is used as a cognition enhancer for the treatment of Alzheimer's disease [39], and roflumilast on the scopolamine induced memory deficit in rats using the object recognition task (ORT).

\section{Materials and methods}

\subsection{Animals}

All experimental procedures were approved by the local ethical committee of the Maastricht University for animal experiments and met the governmental guidelines and EU guidelines for the care and use of laboratory animals. Twenty-four seven monthsold male C57BL/6NCrl mice (Charles River, L'Arbresle, France) were used for the OLT, spatial Y-maze, and xylazine/ketamine induced $\alpha 2$-adrenergic receptor-mediated anesthesia test. Average body weight was $27.6 \mathrm{~g}$ at the beginning of the study. Twenty-four male Wistar rats were supplied by Charles River (Sulzfeld, Germany) and tested between 3-4 months of age in the ORT. Average body weight at the beginning of the study was $345 \mathrm{~g}$. All animals were housed individually in standard individually ventilated cages on sawdust bedding in an air-conditioned room (about $21^{\circ} \mathrm{C}$ ). They were kept on a $12 / 12 \mathrm{~h}$ reversed light/dark cycle (lights on from 19.00 to 7.00 $\mathrm{h}$ ) and had free access to food and water. Animals were housed in the same room as where they were tested. A radio, which was playing softly, provided background noise in the room. All testing was done between 9.00 and $18.00 \mathrm{~h}$. All behavioral experiments were performed in a randomized blinded setup. The sample size was calculated based on a power analysis using historical data on rolipram treatment in the object recognition/location task [16,35,38]. For the murine studies, all mice were subject chronologically to the object location task, the spatial Y-maze, and xylazine/ketamine test with a one-week-interval between the tasks.

\subsection{Treatments}

\subsubsection{Object location and spatial Y-maze in mice}

Drugs were prepared daily. For testing in mice, both roflumilast (a kind gift of BioCrea, Radebeul, Germany; MW 403.21) and rolipram (Sigma-Aldrich St. Louis, USA; MW 275.34) were dissolved in dimethylsulfoxide (DMSO) and kept at $4{ }^{\circ} \mathrm{C}$; this stock solution was used for further dilutions in $0.5 \%$ methylcellulose. Roflumilast and rolipram were used in form of its free base. All injected solutions consisted of $0.5 \%$ methylcellulose with a fixed DMSO percentage (1.2\%) (vehicle). Doses of $0.01,0.03$ and $0.1 \mathrm{mg} / \mathrm{kg}$ of rolipram or roflumilast or vehicle were administered subcutaneously (s.c.). Based on previous findings, PDE4-I administration was performed $3 \mathrm{~h}$ after the learning trial as this has an optimum effect on object memory performance [40]. Injection volume was $5 \mu \mathrm{l} / \mathrm{g}$.

\subsubsection{Object recognition in rats}

For testing in rats, roflumilast (kindly provided by Takeda, Konstanz, Germany; MW 403.21) was dissolved in 98\% methylcellulose solution (0.5\% methylcellulose) and $2 \%$ Tween 80 . Roflumilast in doses of 0 (vehicle), 0.0001, 0.0003, 0.001, 0.003, 0.01 and 
$0.03 \mathrm{mg} / \mathrm{kg}$ was administered intraperitonally (i.p.). Scopolamine (scopolamine hydrobromide; Sigma-Aldrich St. Louis, USA) and donepezil (donepezil hydrochloride; a kind gift from Solvay, Weesp, the Netherlands) were both dissolved in saline $(0.9 \% \mathrm{NaCl})$. Scopolamine was administered i.p. at a dose of $0.1 \mathrm{mg} / \mathrm{kg}$, which has been shown to reliably impair object recognition memory [41]. Donepezil was dissolved in saline and administered orally (p.o.) at a dose of $0.1 \mathrm{mg} / \mathrm{kg}$, which has been shown to be a sub-efficacious dose, not having an effect on object recognition memory [41]. All compounds were administered $30 \mathrm{~min}$ before the learning trial and injection volumes were $1 \mathrm{ml} / \mathrm{kg}$.

\subsubsection{Xylazine/ketamine test in mice}

All solutions were prepared daily. The anesthetic solution consisted of xylazine (CEVA Santé Animale, Naaldwijk, the Netherlands) $(10 \mathrm{mg} / \mathrm{kg})$ and ketamine (Eurovet Animal Health, Bladel, the Netherlands) $(60 \mathrm{mg} / \mathrm{kg})$. Injections were given i.p. and injection volume was $1.1 \mu \mathrm{l} / \mathrm{g}$. Doses of $0.03,0.3$ and $3.0 \mathrm{mg} / \mathrm{kg}$ roflumilast, 0.03 and $3.0 \mathrm{mg} / \mathrm{kg}$ rolipram, or vehicle, were administered $15 \mathrm{~min}$ after anesthesia induction. Injection volume was $5 \mu \mathrm{l} / \mathrm{g}$ (s.c.).

\subsection{Behavioral analyses}

\subsubsection{Object location in mice}

The OLT was performed as described elsewhere [42]. The apparatus consisted of a circular arena, $40 \mathrm{~cm}$ in diameter. Half of the $40 \mathrm{~cm}$ high transparent polyvinyl chloride wall was covered from the outside with white paper. Two objects were placed symmetrically about $10 \mathrm{~cm}$ away from the wall on the separation line, between the transparent and the covered side of the arena. Four different sets of objects were available: (1) a cone made of brass (maximal diameter $6 \mathrm{~cm}$ and total height $3.8 \mathrm{~cm}$ ), (2) a transparent glass bottle (diameter $2.7 \mathrm{~cm}$, height $8.5 \mathrm{~cm}$ ) filled with sand and water, (3) a massive metal cube $(2.5 \mathrm{~cm} \times 5 \mathrm{~cm} \times 7.5 \mathrm{~cm})$ with two holes (diameter $1.5 \mathrm{~cm}$ ), and (4) a massive aluminum cube with a tapering top $(4.5 \mathrm{~cm} \times 4.5 \mathrm{~cm} \times 8.5 \mathrm{~cm})$. Objects and locations were presented to the animals in a balanced manner to avoid object or place biases. A testing session comprised two trials of $4 \mathrm{~min}$. Before each trial, mice were placed in an empty Makrolon cage (incubation cage) for $4 \mathrm{~min}$, to prime their attention. During the first learning trial (T1) two identical objects were placed symmetrically about $10 \mathrm{~cm}$ away from the wall on the separation line between the transparent and covered side of the arena. After the first exploration period, the mouse was put back in its home cage. Mice then received their treatment $3 \mathrm{~h}$ post T1. Subsequently, after the normal forgetting inter-trial interval of $24 \mathrm{~h}$, the mouse was placed in the apparatus for the second trial of $4 \mathrm{~min}$ (T2). Two identical objects as in $\mathrm{T} 1$ were used; one object was placed in the previously used position, whereas the other was placed in a novel position which could be either a fixed distance toward the front or a fixed distance toward the back of the arena. The times spent exploring each object during $\mathrm{T} 1$ and $\mathrm{T} 2$ were recorded manually using a personal computer by an experimenter unaware of the conditions being tested. Exploration was defined in the following manner: directing the nose to the object at a distance of no more than $2 \mathrm{~cm}$ and/or touching the object with the nose. Sitting on the object was not considered as exploratory behavior. To avoid olfactory cues, the objects were thoroughly cleaned with $70 \%$ ethanol after each trial. The testing order of conditions was determined randomly. T1 was always on Monday and Thursday in order to have a sufficient wash-out period between compound sessions. Prior to compound testing, animals were handled daily and adapted to the procedures in two days, i.e., they were allowed to explore the apparatus twice for $3 \mathrm{~min}$ each day. All four objects used in this study were presented in these two subsequent days. Thereafter, animals were adapted to the compound administration by one s.c. vehicle injection.

The time spent exploring the two identical objects in $\mathrm{T} 1$ was indicated as "a1" and "a2", respectively. The time spent exploring the familiar and the new location in T2 was indicated as "a" and "b", respectively. The following variables were calculated: $\mathrm{e} 1=\mathrm{a} 1+\mathrm{a} 2$; $e 2=a+b$ and $d 2=(b-a) / e 2$. e1 and e2 are measures of the total exploration time of both objects during $\mathrm{T} 1$ and $\mathrm{T} 2$, respectively. $\mathrm{d} 2$ is a relative measure of discrimination, corrected for exploration activity (e2). This $\mathrm{d} 2$ index can range from -1 to 1 , with 1 indicating complete preference for the novel location/object and 0 signifying no preference for either location/object. Animals with an e1 or e2 lower than $7.5 \mathrm{~s}$ were excluded since this does not allow to reliably measure memory performance [43].

\subsubsection{Spatial Y-maze in mice}

After completion of the OLT test, the Y-maze spatial memory test was performed using a Y-maze consisting of three equal arms, with each arm being separated from the others at a $120^{\circ}$ angle $[44,45]$. Each arm was $40 \mathrm{~cm}$ long, $17 \mathrm{~cm}$ high, $4 \mathrm{~cm}$ wide at the bottom and $13 \mathrm{~cm}$ wide at the top. In the task, one arm was made inaccessible due to a removable blockade placed in front of the arm during trial one. The blocked arm was randomly alternated among the different trials. In between trials, the maze was cleaned thoroughly with a $70 \%$ ethanol solution to reduce olfactory biases. A mouse was placed in one of the open arms (termed the 'start arm', which was randomized over groups) and allowed to explore the two open arms of the maze for $5 \mathrm{~min}$. One arm visit required that both hind paws of the animal had to be placed completely inside the arm. Mice received treatment at $3 \mathrm{~h}$ after the first learning trial. After a $24 \mathrm{~h}$ interval, the mouse was placed back into its corresponding start arm, but now the blockade had been removed, providing access to the previously blocked arm (termed the 'novel arm'). Spatial memory was assessed by the amount of time spent in the novel arm, which had to be significantly more than $33.33 \%$, corrected for the latency to move from the start arm to another arm and the amount of time the animal spent in the center of the maze. The times spent exploring each arm was recorded using Ethovision (Noldus, the Netherlands). Also, the total distance the mouse had traveled in the Y-maze was measured, to rule out any effects caused by differences in activity level.

\subsubsection{Xylazine/ketamine induced $\alpha 2$-adrenergic receptor-mediated anesthesia test in mice}

Given the emetic properties of PDE4-Is, the ability of roflumilast to shorten xylazine/ketamine induced $\alpha 2$-adrenergic receptormediated anesthesia was measured one week after completion of the Y-maze test. Since mice are a non-vomiting species, the xylazine/ketamine anesthesia test, a well-established surrogate marker for emesis in mice, was applied [32]. The earlier the treated mice recover their righting reflex upon anesthesia the more competition there is on the $\alpha 2$-adrenergic receptor. Xylazine (CEVA Santé Animale, Naaldwijk, the Netherlands) $(10 \mathrm{mg} / \mathrm{kg})$ and ketamine (Eurovet Animal Health, Bladel, the Netherlands) $(60 \mathrm{mg} / \mathrm{kg}$ ) was given intraperitoneal (i.p.) to induce anesthesia (injection volume: $1.1 \mu \mathrm{l} / \mathrm{g}$ ) [35]. Rolipram, roflumilast or vehicle were administered 15 min after induction of anesthesia and the mouse was placed in a dorsal position awaiting recovery. The time-delay to the recovery toward the righting reflex (four paws on the floor) was used as an endpoint to measure the time to regain their righting reflex. Animals regaining their righting reflex before the treatment injection or not displaying a righting reflex within $2 \mathrm{~h}$ were excluded from analysis. 


\subsubsection{Object recognition in rats}

Rats were tested in the ORT which was performed as described elsewhere $[38,43]$. The apparatus consisted of a circular arena, $83 \mathrm{~cm}$ in diameter. The back half of the $40 \mathrm{~cm}$ high wall was made of gray polyvinyl chloride (PVC) and the front was made of transparent PVC. Two objects were placed in symmetrical positions at the mid-line between the gray and transparent halves of the arena, about $10 \mathrm{~cm}$ away from the wall. Four sets of 3 identical objects were used: (1) a standard 11 brown transparent glass bottle (diameter $10 \mathrm{~cm}$, height $22 \mathrm{~cm}$ ) filled with water, (2) a metal cube $(10.0 \times 5.0 \times 7.5 \mathrm{~cm})$ with two holes (diameter $1.9 \mathrm{~cm})$, (3) a cone consisting of a gray polyvinyl chloride base (maximal diameter $18 \mathrm{~cm}$ ) with a collar on top made of brass (total height $16 \mathrm{~cm}$ ), and (4) an aluminum cube with a tapering top $(13.0 \times 8.0 \times 8.0 \mathrm{~cm})$. Objects were presented to the animals in a balanced manner to avoid object or place biases. A test session comprised two trials, each with durations of $3 \mathrm{~min}$. During the learning trial (T1) the apparatus contained two identical objects (object a1 and a2). Subsequently, rats were put back in their home cage for a $1 \mathrm{~h}$ interval. After the retention interval, rats were put back into the arena for the test trial (T2). In T2, the two objects from T1 are replaced by one identical copy "a" and a different novel object "b". The times spent in exploring each object during $\mathrm{T} 1$ and $\mathrm{T} 2$ were recorded manually on a personal computer using the same criteria as for mice. In order to avoid the presence of olfactory cues, the objects were thoroughly cleaned with a $70 \%$ ethanol solution before each trial. The discrimination index (d2) was determined as described for mice. Testing was always on Monday, Wednesday or Friday in order to have a sufficient wash-out period between compound sessions. Prior to compound testing, rats were handled and adapted to the procedures and compound administration similarly as with the mice. All rats showed sufficient exploration to have a reliable memory performance [43].

\subsection{Pharmacokinetics}

After behavioral testing all mice were subsequently used for the determination of plasma and brain concentrations following s.c. administration. Pharmacokinetic (PK) measurements were expected to be close to the detection limit after dosing with the behaviorally active dose of $0.03 \mathrm{mg} / \mathrm{kg}$ of both compounds in the OLT. For this reason doses were increased and animals were sacrificed for blood and brain sampling at $30 \mathrm{~min}$ and $21 \mathrm{~h}$ after dosing of 0.3 or $3 \mathrm{mg} / \mathrm{kg}$. For rolipram 11 animals were used and for roflumilast 12 animals; $n=3$ per time point (except for the $3 \mathrm{mg} / \mathrm{kg}$ rolipram condition, $n=2$ ).

Blood was drawn from the saphenous vein using heparincoated tubes (Microcuvette CB300, Sarstedt, Germany), which were temporarily stored on ice and then centrifuged within $15 \mathrm{~min}$ of collection. Plasma was isolated using centrifugation $(1500 \times g$ for $10 \mathrm{~min}$ at $4{ }^{\circ} \mathrm{C}$ ) and pipetted into vials. Immediately after blood collection the animal was decapitated. The complete brain was collected, rinsed with ice-cold saline, placed in a cup and weighed. Plasma and brain samples were immediately stored at $-80^{\circ} \mathrm{C}$ until analytical processing. Roflumilast, roflumilast-N-oxide and rolipram were quantified by Agilux laboratories (Worcester, USA). Roflumilast-N-oxide was measured in the same samples as roflumilast. For analytical sample preparation, plasma was used as is, while brain samples were first homogenized in 80:20 water:acetonitrile. Both matrices were processed for drug quantification using liquid-liquid extraction methodology followed by a characterized liquid chromatography-tandem mass spectrometry (LC-MS/MS) assay. Standard curves were prepared in control matrices, an appropriate dynamic range was achieved, and instrument settings and potentials were adjusted to optimize the MS signal for the compounds using Masslynx software with the Quanlynx appli-

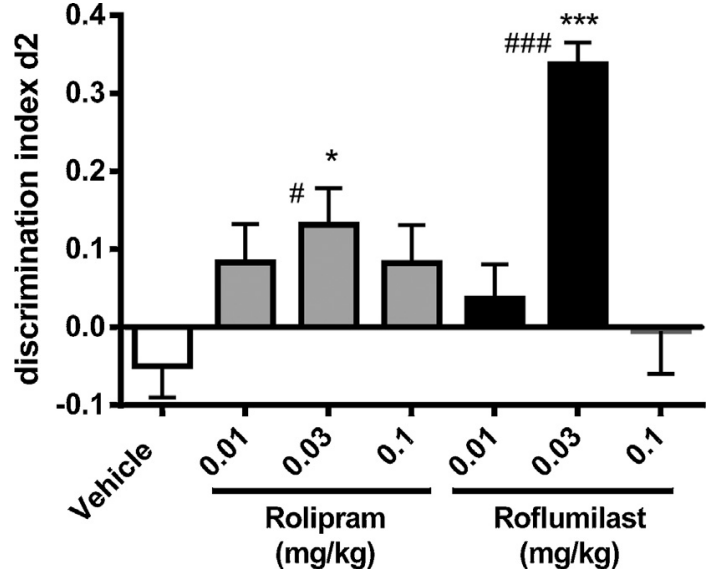

Fig. 1. Effects of rolipram (s.c.) and roflumilast (s.c.) on the discrimination index (d2) in an object location task after a $24 \mathrm{~h}$ retention interval in 7 months old $\mathrm{C} 57 \mathrm{BL} / 6 \mathrm{NCrl}$ mice (means + SEMs). The $\mathrm{d} 2$ index of the rolipram and roflumilast $0.03 \mathrm{mg} / \mathrm{kg}$ dose conditions were significantly higher than zero, i.e., indicating discrimination between object locations (one-sample t-tests: \#: $p<0.05$, \#\#\#: $p<0.001$ ). When compared with vehicle treatment, both these rolipram and roflumilast conditions had a significantly higher $\mathrm{d} 2$ index. A significant difference from the vehicle condition is depicted with asterisks (Dunnett's multiple comparison test: ${ }^{*}: p<0.05$, ${ }^{* * *}$ : $p<0.001) . n=15-24$ per condition.

cation manager (Waters Ltd.). For both roflumilast and rolipram the lowest level of quantification (LLOQ) was $0.5 \mathrm{ng} / \mathrm{ml}$ for plasma and $1.25 \mathrm{ng} / \mathrm{g}$ for brain. If the plasma concentration $\left(C_{\mathrm{p}}\right)$ or brain concentration $\left(C_{\mathrm{b}}\right)$ of a sample was below the quantification limit (BQL), but one or more of the other samples in the same compound/dose group had measurable values, the BQL was treated as zero.

\subsection{Statistics}

One-sample t-statistics were performed in order to assess whether the $\mathrm{d} 2$ index for each treatment condition differed significantly from zero (chance level) in the OLT or ORT. Effects between treatment conditions were analyzed using a one-way ANOVA, followed by a post-hoc analysis with Dunnett's multiple comparison test. In the Y-maze, one-sample t-statistics were used to assess whether the percentage of time spent in the novel arm for each treatment condition differed significantly from 33.33\% (chance level). Differences between treatment conditions in the Y-maze were analyzed using a one-way ANOVA followed by Dunnett's multiple comparison test. The latter analysis was also applied in the xylazine/ketamine test. An $\alpha$ level of 0.05 was considered significant.

\section{Results}

\subsection{Memory}

In the OLT, the exploration times between treatment conditions for both $\mathrm{T} 1(\mathrm{e} 1: F(6,113)=1.27$, n.s. $)$ and $\mathrm{T} 2(\mathrm{e} 2: F(6,113)=1.66$, n.s.) were comparable (data not shown). One mouse was excluded from the analysis in the rolipram $0.1 \mathrm{mg} / \mathrm{kg}$ and roflumilast $0.01 \mathrm{mg} / \mathrm{kg}$ condition, due to insufficient exploration times (<7.5 s). One-sample $t$-tests showed that the $\mathrm{d} 2$ indices of the rolipram $0.03 \mathrm{mg} / \mathrm{kg}$ and roflumilast $0.03 \mathrm{mg} / \mathrm{kg}$ conditions significantly differed from zero, indicating that mice discriminated between locations of the objects after $24 \mathrm{~h}$ (Fig. 1). Comparisons between rolipram conditions showed significant differences $(F(3,68)=3.99$, $p<0.05$ ). Post-hoc analysis revealed that the $\mathrm{d} 2$ index in the rolipram $0.03 \mathrm{mg} / \mathrm{kg}$ condition differed significantly from the vehicle condition (Fig. 1). Between group comparisons of the roflumilast 


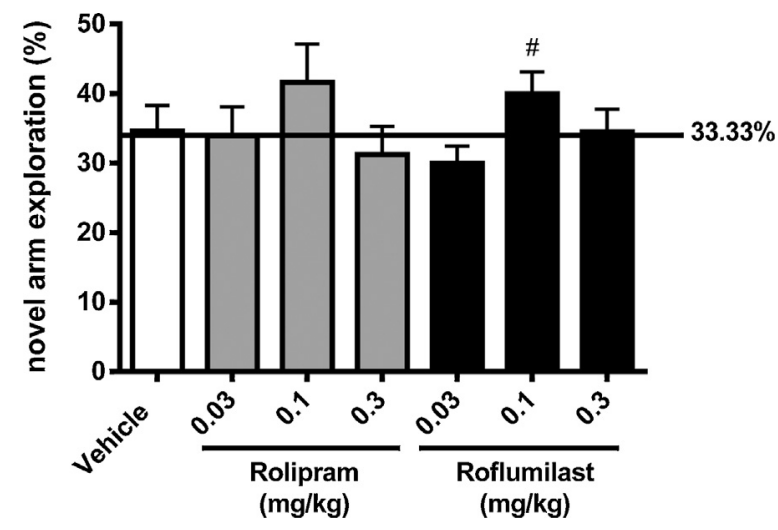

Fig. 2. Effects of rolipram (s.c.) and roflumilast (s.c.) on novel arm exploration (\%) in the spatial Y-maze after a $24 \mathrm{~h}$ retention interval in 7 months old $\mathrm{C} 57 \mathrm{BL} / 6 \mathrm{NCrl}$ mice (means + SEMs). The $0.1 \mathrm{mg} / \mathrm{kg}$ dose of roflumilast differed from chance performance with a novel arm performance above $33.33 \%$ (one-sample $t$-test; $\#: p<0.05$ ). When compared with the vehicle condition, neither rolipram, nor roflumilast had a significant effect on novel arm exploration in the Y-maze. $n=21-23$ per condition.

conditions also showed significant differences $(F(3,68)=15.71$, $p<0.001)$. Post-hoc analysis revealed that the $\mathrm{d} 2$ index of the roflumilast $0.03 \mathrm{mg} / \mathrm{kg}$ condition differed significantly from the vehicle condition (Fig. 1).

Subsequently, the mice were tested for spatial memory in the Y-maze. Herein, the exploration time of the novel arm is quantified as a measure for spatial memory. Before starting the Y-maze experiments, one mouse died for reasons unknown. Further, in the $0.3 \mathrm{mg} / \mathrm{kg}$ rolipram condition, one mouse showed no exploration and one animal ignored one arm completely and these animals were consequently excluded from analysis. The distance moved during the test trial was neither significantly different between the vehicle and rolipram conditions $(F(3,86)=0.46$, n.s. $)$, nor between the vehicle and roflumilast conditions $(F(3,88)=1.64$, n.s.). One-sample $t$-tests showed that the percentage time spent in the novel arm during the second trial was significantly above the chance threshold (33.33\%) only for the roflumilast $0.1 \mathrm{mg} / \mathrm{kg}$ condition $(t(22)=2.11, p<0.05)$ (Fig. 2). However, comparisons between treatment conditions showed no significant difference on novel arm exploration between vehicle and roflumilast conditions $(F(3,88)=1.64$, n.s $)$ or vehicle and rolipram conditions $(F(3,86)=0.46$, n.s. $)$.

\subsection{Emetic-like behavior}

The results for both rolipram and roflumilast on the duration of the $\alpha 2$-adrenergic receptor-mediated anesthesia are shown in Fig. 3. One mouse was excluded because it showed the righting reflex before being treated with $0.3 \mathrm{mg} / \mathrm{kg}$ roflumilast. Rolipram treatment significantly affected the duration of xylazine/ketamineinduced anesthesia $(F(2,33)=8.10, p<0.001)$. Post-hoc analysis showed that the rolipram $0.3 \mathrm{mg} / \mathrm{kg}$ condition had a significantly reduced delay until the righting reflex compared with the vehicle condition (Fig. 3). Roflumilast conditions also differed significantly from the vehicle condition $(F(3,42)=2.90, p<0.05)$. Post-hoc analysis showed a reduced righting reflex delay for the $3.0 \mathrm{mg} / \mathrm{kg}$ roflumilast condition (Fig. 3).

\subsection{Pharmacokinetics}

Respectively, $0.5 \mathrm{~h}$ and $21 \mathrm{~h}$ after administration, rolipram or roflumilast and its active metabolite roflumilast $\mathrm{N}$-oxide were measured in the plasma and brain of the mice. $0.5 \mathrm{~h}$ after administration of a dose of $3 \mathrm{mg} / \mathrm{kg}$ of either compound, rolipram or roflumilast and roflumilast $\mathrm{N}$-oxide were readily detectable in plasma and

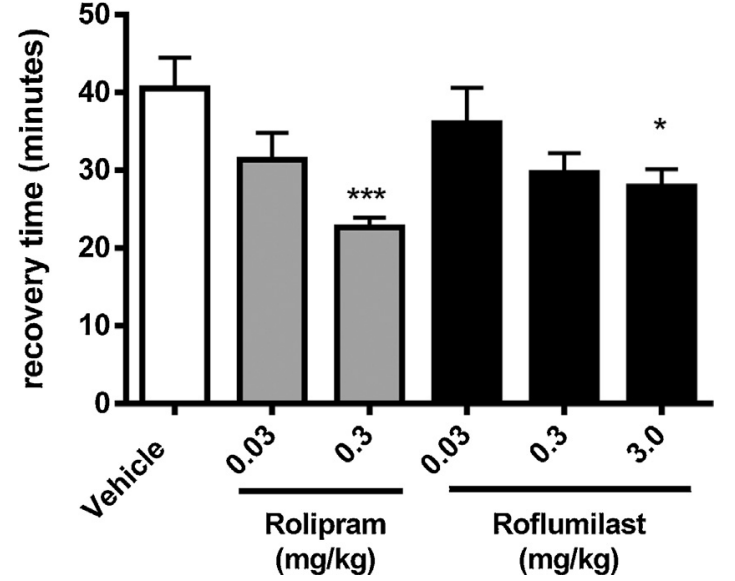

Fig. 3. Effects of roflumilast (s.c.) and rolipram (s.c.) on the duration of anesthesia ( $\mathrm{min})$ induced by the combination of xylazine $(10 \mathrm{mg} / \mathrm{kg}$, i.p.) and ketamine $(60 \mathrm{mg} / \mathrm{kg}$, i.p) in $\mathrm{C} 57 \mathrm{BL} / 6 \mathrm{NCrl}$ mice. Fifteen minutes following the induction of anesthesia, mice were treated with of rolipram or roflumilast. The duration of anesthesia was assessed by the return of righting reflex (means + SEMs). When compared with the vehicle condition, $0.3 \mathrm{mg} / \mathrm{kg}$ rolipram significantly reduced the anesthesia time. Roflumilast only showed a tendency toward a reduced anesthesia time at the $3.0 \mathrm{mg} / \mathrm{kg}$ condition, compared with vehicle (Dunnett's multiple comparison test: *: $p<0.05,{ }^{* * *}: p<0.001 . n=11-12$ per condition.

Table 1

Pharmacokinetics of roflumilast, roflumilast $\mathrm{N}$-oxide and rolipram in the mouse.

\begin{tabular}{|c|c|c|}
\hline Interval & $0.5 \mathrm{~h}$ & $21 \mathrm{~h}$ \\
\hline \multicolumn{3}{|l|}{ Roflumilast (0.3 mg/kg) } \\
\hline$C_{\mathrm{p}}(\mathrm{ng} / \mathrm{ml})$ & $14.90(1.72)$ & BQL \\
\hline$C_{\mathrm{b}}(\mathrm{ng} / \mathrm{g})$ & $13.83(2.47)$ & BQL \\
\hline$C_{\mathrm{b}}: C_{\mathrm{p}}$ & $0.97(0.25)$ & BQL \\
\hline \multicolumn{3}{|l|}{ Roflumilast (3 mg/kg) } \\
\hline$C_{\mathrm{p}}(\mathrm{ng} / \mathrm{ml})$ & $69.27(17.03)$ & 7.87 (n.a.) \\
\hline$C_{\mathrm{b}}(\mathrm{ng} / \mathrm{g})$ & $45.77(14.40)$ & $\mathrm{BQL}$ \\
\hline$C_{\mathrm{b}}: C_{\mathrm{p}}$ & $0.88(0.44)$ & $\mathrm{BQL}$ \\
\hline \multicolumn{3}{|l|}{ Roflumilast $\mathrm{N}$-oxide $(0.3 \mathrm{mg} / \mathrm{kg})$} \\
\hline$C_{\mathrm{p}}(\mathrm{ng} / \mathrm{ml})$ & $3.83(0.78)$ & $\mathrm{BQL}$ \\
\hline$C_{\mathrm{b}}(\mathrm{ng} / \mathrm{g})$ & $\mathrm{BQL}$ & BQL \\
\hline$C_{\mathrm{b}}: C_{\mathrm{p}}$ & BQL & $\mathrm{BQL}$ \\
\hline \multicolumn{3}{|l|}{ Roflumilast N-oxide (3 mg/kg) } \\
\hline$C_{\mathrm{p}}(\mathrm{ng} / \mathrm{ml})$ & $15.53(2.76)$ & $0.58(0.29)$ \\
\hline$C_{\mathrm{b}}(\mathrm{ng} / \mathrm{g})$ & 0.44 (n.a.) & $\mathrm{BQL}$ \\
\hline$C_{\mathrm{b}}: C_{\mathrm{p}}$ & 0.08 (n.a.) & BQL \\
\hline \multicolumn{3}{|l|}{ Rolipram $(0.3 \mathrm{mg} / \mathrm{kg})$} \\
\hline$C_{\mathrm{p}}(\mathrm{ng} / \mathrm{ml})$ & $46.50(6.89)$ & BQL \\
\hline$C_{\mathrm{b}}(\mathrm{ng} / \mathrm{g})$ & $65.05(4.95)$ & $\mathrm{BQL}$ \\
\hline$C_{\mathrm{b}}: C_{\mathrm{p}}$ & $1.63(0.06)$ & $\mathrm{BQL}$ \\
\hline \multicolumn{3}{|l|}{ Rolipram (3 mg/kg) } \\
\hline$C_{\mathrm{p}}(\mathrm{ng} / \mathrm{ml})$ & $433.67(125.06)$ & BQL \\
\hline$C_{\mathrm{b}}(\mathrm{ng} / \mathrm{g})$ & $596.67(178.67)$ & $\mathrm{BQL}$ \\
\hline$C_{\mathrm{b}}: C_{\mathrm{p}}$ & $2.11(1.35)$ & BQL \\
\hline
\end{tabular}

Neuropharmacokinetics of roflumilast, roflumilast N-oxide and rolipram (0.3 and $3 \mathrm{mg} / \mathrm{kg}$, s.c.) 0.5 and $21 \mathrm{~h}$ after administration ( $n=3$ per condition, except rolipram $3 \mathrm{mg} / \mathrm{kg}$ with $n=2)$. Total plasma $\left(C_{\mathrm{p}}\right)$ and total brain $\left(C_{\mathrm{b}}\right)$ concentrations are reported as means $( \pm$ SEMs). For all compounds, the LLOQ for plasma and brain were $0.5 \mathrm{ng} / \mathrm{ml}$ and $1.25 \mathrm{ng} / \mathrm{g}$, respectively. n.a.: not applicable; BQL: below quantification limit.

brain (Table 1). Administration of $0.3 \mathrm{mg} / \mathrm{kg}$ of rolipram or roflumilast yielded similar results, although roflumilast $\mathrm{N}$-oxide was not detected in the brain anymore. However, $21 \mathrm{~h}$ after administration, only with the high dose of $3 \mathrm{mg} / \mathrm{kg}$, roflumilast and its metabolite were still detected and in plasma only.

\subsection{Combination therapy}

First, a dose-response experiment was performed in the scopolamine-induced memory deficit model to determine a sub- 

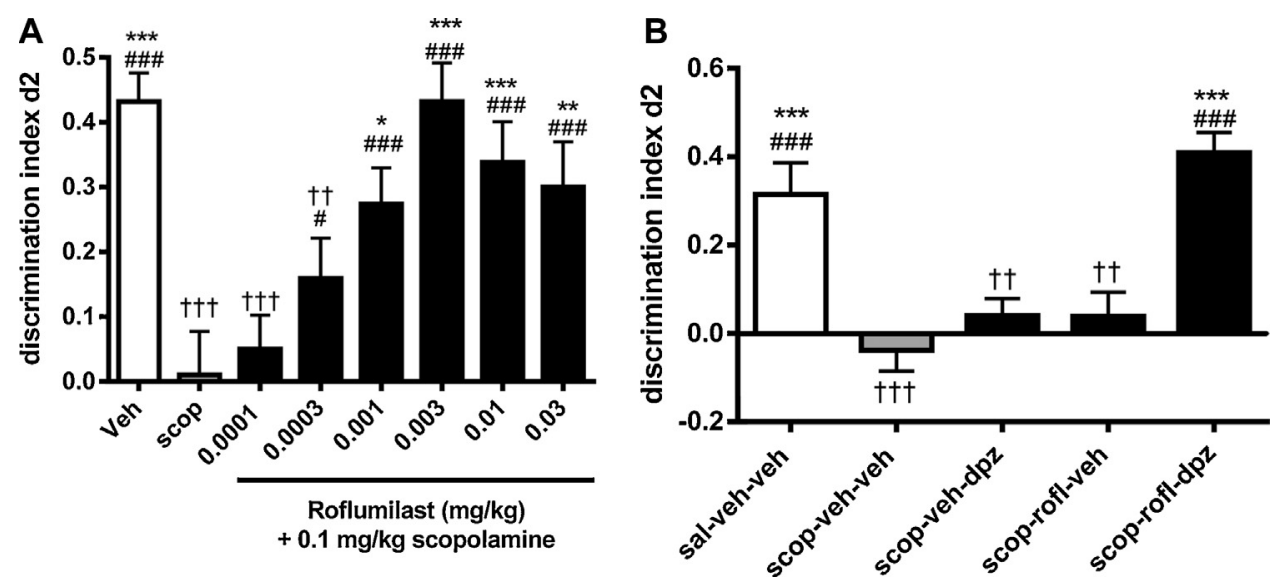

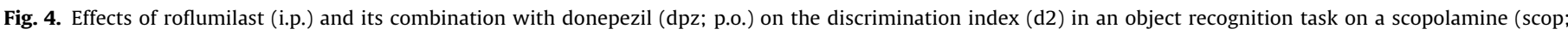

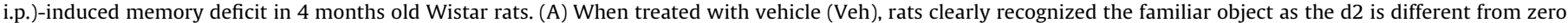

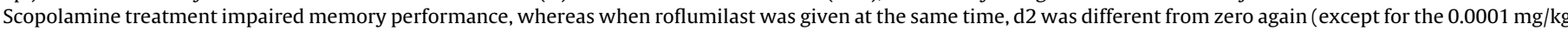

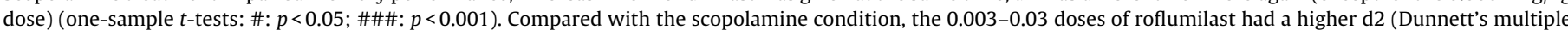

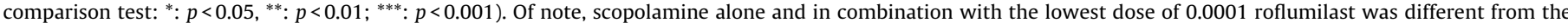

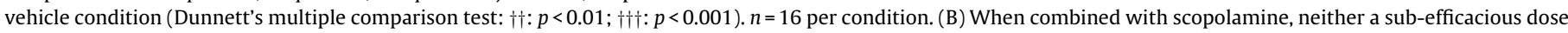

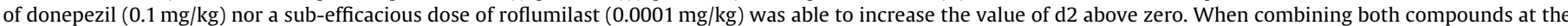

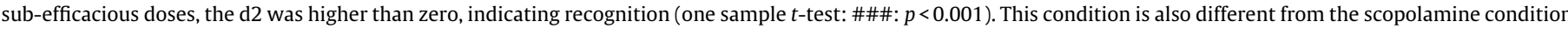

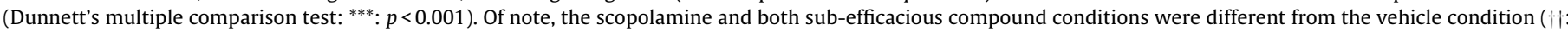
$p<0.01$; $(\dagger \dagger+: p<0.001) . n=24$ per condition.

efficacious dose of roflumilast. No significant differences between treatment conditions were observed in the level of exploration in $\mathrm{T} 1(\mathrm{e} 1: F(7,120)=1.09$, n.s. $)$ and $\mathrm{T} 2(\mathrm{e} 2: F(7,120)=0.82$, n.s. $)$ (data not shown). One sample $t$-tests showed that the $\mathrm{d} 2$ indices of the $0.0003-0.03 \mathrm{mg} / \mathrm{kg}$ roflumilast dose conditions were significantly higher than zero, just as was the case for the vehicle condition, while after scopolamine treatment the $\mathrm{d} 2$ index was equal to zero (Fig. $4 \mathrm{~A}$ ). The $\mathrm{d} 2$ index was different between treatment conditions $(F(3,81)=6.67, p<0.001)$ and post-hoc analyses showed that the vehicle, $0.001 \mathrm{mg} / \mathrm{kg}, 0.003 \mathrm{mg} / \mathrm{kg}, 0.01 \mathrm{mg} / \mathrm{kg}$ and $0.03 \mathrm{mg} / \mathrm{kg}$ conditions had a significantly higher $\mathrm{d} 2$ value compared to the scopolamine condition (Fig. 4A). On the other hand, only the scopolamine, $0.0001 \mathrm{mg} / \mathrm{kg}$, and $0.0003 \mathrm{mg} / \mathrm{kg}$ conditions were significantly lower compared to the vehicle condition.

Next we tested the combination of the previously established sub-efficacious dose of roflumilast and the nootropic donepezil, also at a sub-efficacious dose $(0.1 \mathrm{mg} / \mathrm{kg})$, in the scopolamineinduced memory deficit model. There were no differences between treatment conditions in the level of exploration in $\mathrm{T} 1$ (e1: $F(4,115)=0.44$, n.s.) and T2 (e2: $F(4,115)=1.46$, n.s.) (data not shown). One sample $t$-tests showed that only the $\mathrm{d} 2$ index of the vehicle and the combination of roflumilast and donepezil upon scopolamine were significantly higher than zero (Fig. 4B). The other treatment conditions showed no differences from chance performance. A significant differences in $\mathrm{d} 2$ between treatment conditions was found $(F(4,115)=13.78, p<0.001)$ and post-hoc analyses showed that the vehicle and the combined treatments of roflumilast and donepezil had a significantly higher $\mathrm{d} 2$ index when compared with scopolamine alone. At the same time, separate testing conditions of scopolamine, donepezil and roflumilast were all significantly lower when compared with the vehicle condition (Fig. 4B).

\section{Discussion}

We found that the PDE4-I roflumilast appears equally potent (OLT) than the classic PDE4-I rolipram in improving spatial memory of mice. The potential to induce emesis appears to be at least 10 times lower in roflumilast when compared with rolipram. Combining sub-efficacious doses of roflumilast and donepezil reversed a scopolamine-induced memory deficit of rats in the ORT. Importantly, none of the compounds had any effects on exploratory activity which could have influenced memory performances.

PDE4 inhibition has been studied intensively using the PDE4I rolipram and it was found to enhance cognition in various experimental animal models including healthy, age- and pharmacologically impaired, and transgenic Alzheimer mice models (for reviews see Refs. [17-19]). However, PDE4 inhibition in humans results in unwanted side effects including emesis [9,25,26]. Recently, new generation PDE4-Is including MK-0952, HT-0712, D159687, and Gebr-7b were developed and all were shown preclinically to improve memory [46-48]. In addition, emetic effects were reduced in rodents or monkeys (e.g., Gebr-7b [35] and D159687 [10], respectively). Until now only roflumilast made it to the clinic because of its favorable emetic/clinical profile in humans, though this has been demonstrated for the FDA approved treatment of COPD $[29,30]$. Both rolipram and roflumilast inhibit most PDE4 isoforms, in particular the PDE4B and PDE4D isoforms in the hippocampus [49]. Interestingly, when compared with rolipram, roflumilast has a preferable emetic profile as emetic effects were demonstrated in fewer human subjects and emesis appears to be only nausea-related without effects on vomiting [28], suggesting a difference in intrinsic properties still.

When directly comparing doses of roflumilast with the PDE4-I rolipram, both compounds were equally effective $(0.03 \mathrm{mg} / \mathrm{kg}$, s.c.) in improving OLT performance of mice. Interestingly, the discrimination index (d2) for the roflumilast treatment group displayed an even higher absolute value compared with the rolipram treatment group, indicating that roflumilast may have a stronger impact on spatial memory performance. The optimal dose of rolipram was in line with previous studies [46]. The potent effect of roflumilast was further confirmed by the data of the spatial Y-maze test, where the effective dose of roflumilast differed significantly from vehicle at an effective dose of $0.1 \mathrm{mg} / \mathrm{kg}$ (s.c.). The same dose of rolipram did not show a significant improvement in spatial memory, yet this might be prevalent with higher power.

Since emesis is a side-effect of PDE4-Is in general, this measure was investigated using the xylazine/ketamine induced $\alpha 2$ adrenergic receptor-mediated anesthesia task. Rolipram showed a strong effect on emetic-like effect with a dose $(0.3 \mathrm{mg} / \mathrm{kg}) 10$ times 
higher than the effective dose of $0.03 \mathrm{mg} / \mathrm{kg}$ in the OLT. In contrast, roflumilast showed an emetic potential only at a dose $(3 \mathrm{mg} / \mathrm{kg}) 100$ times the effective dose of $0.03 \mathrm{mg} / \mathrm{kg}$ in the OLT and 30 times the effective dose of $0.1 \mathrm{mg} / \mathrm{kg}$ in the spatial Y-maze. Based on these data, the emetic potential of roflumilast is estimated to be more than 10 times lower than that of rolipram.

The dose-response study evaluated the effects of different doses of roflumilast in a memory deficit model, induced by the muscarinic acetylcholine receptor antagonist scopolamine. The $\mathrm{d} 2$ comparisons with the scopolamine condition revealed that roflumilast was able to fully restore object recognition memory function in rats at doses of $0.001-0.03 \mathrm{mg} / \mathrm{kg}$ (i.p.). Whereas, single sub-efficacious doses of roflumilast $(0.0001 \mathrm{mg} / \mathrm{kg})$ and donepezil $(0.1 \mathrm{mg} / \mathrm{kg})$ could not reverse the scopolamine-induced deficit, testing the combination of both compounds at these sub-efficacious doses completely reversed the scopolamine-induced deficit. This suggest that the procognitive effects of both AChE-Is and PDE4-Is, which both have dose limitations due to primarily gastrointestinal side-effects including emesis $[9,25,26,50]$, could be enhanced when combined at low doses.

The approximate cerebral blood volume relative to total unperfused brain volume is 0.04 [51], thus a $C_{\mathrm{b}} / C_{\mathrm{p}}$ of $>0.04$ indicates that a compound is brain penetrant. The $C_{\mathrm{b}} / C_{\mathrm{p}}$ of roflumilast in our mice is close to 1 , clearly indicating that the compound is brain penetrant. However, the metabolite roflumilast $\mathrm{N}$-oxide is less brain penetrant with a $C_{\mathrm{b}} / C_{\mathrm{p}}$ of 0.08 . Likewise, it has very recently been demonstrated that roflumilast is clearly brain penetrant, and to a lower degree its metabolite, after 10 days of treatment in hypertensive rats [47]. In that particular study roflumilast was also able to ameliorate the hypertension-induced memory deficit of the rats in the ORT, again supporting a procognitive effect of roflumilast.

Between doses we assume linear concentrations in plasma and brain as has been demonstrated for roflumilast [47]. Extrapolating our PK measurements to the behaviorally active dose of $0.03 \mathrm{mg} / \mathrm{kg}$ in the OLT, one could expect a total $C_{\mathrm{b}}$ of $4.18 \mathrm{ng} / \mathrm{ml}(10.37 \mathrm{nM})$ in the brain. PDE4D is assumed to be the most important PDE4 subtype for memory function [34,52] and the IC50 value of roflumilast for PDE4D inhibition is maximally $0.4 \mathrm{nM}$ [49]. To our knowledge, only the free fraction in plasma has been very well established for roflumilast. In humans and pigs the free fraction of roflumilast is about 1 , while in other species it is slightly higher, as is also evident in mice with a free plasma fraction of roflumilast of 3.7\% (personal communication Dr. Hermann Tenor). When assuming an IC50 concentration to be biologically active in the OLT, the hypothetical free fraction in the mouse brain can be calculated, which is (0.4/10.37=) $3.85 \%$. This is very close to the value of $3.7 \%$ of the free plasma fraction. Alternatively, when assuming a similar free fraction of $3.7 \%$ for roflumilast in the brain, this results in a free brain concentration of $0.37 \mathrm{nM}$. Interestingly, this is almost similar to the IC50 for roflumilast. Thus, there are indications that roflumilast is biologically active at least already $30 \mathrm{~min}$ after its administration, thus improving the memory performance of the mice in the OLT. This also accounts for the improved performance in the Y-maze as its optimum dose was approximately three times higher as in the OLT. The contribution of the metabolite in this respect is likely very minor based on the lower potency (PDE4D IC50 is maximally $0.8 \mathrm{nM}$ ) and brain penetration. With respect to roflumilast attenuating the scopolamine-induced memory deficit of rats in the ORT, future PK studies are needed to establish the exact level of PDE4 inhibition.

Rolipram is clearly brain penetrant in our mice with the $C_{\mathrm{b}} / C_{\mathrm{p}}$ around 2, which is very similar to previous studies (e.g., Ref. [53]). As linear concentrations of rolipram in plasma and brain can be assumed [53]. a total $C_{\mathrm{b}}$ of $3.15 \mathrm{ng} / \mathrm{ml}(11.44 \mathrm{nM})$ after the behaviorally active dose of $0.03 \mathrm{mg} / \mathrm{kg}$ in the OLT can be extrapolated from our PK measurements. To our knowledge, in rodents only free fractions of plasma have been established [54-56], which seem to be higher as for instance in other species including pigs. When assuming that the free fraction in the mouse brain is similar to that in the pig brain, i.e., $19.2 \%$ [56], this results in a free brain concentration of $2.20 \mathrm{nM}$ rolipram. This is very close to the IC50 of $3 \mathrm{nM}$ for the rolipram high-affinity binding site [57]. Thus, rolipram appears to be sufficiently biologically active in the brain of our mice to improve the memory performance in the OLT.

In agreement with our previous studies, we observed that a PDE4-I improves late consolidation processes when injected $3 \mathrm{~h}$ after the learning trial. Late consolidation processes are very likely dependent on glutamatergic postsynaptic cAMP/PKA signaling [58]. Based on our PK measurement, both rolipram and roflumilast are not present in brain or plasma anymore at $21 \mathrm{~h}$ after their injection, corresponding to the time point of the test trial in the OLT and Y-maze. This rules out the possibility of PDE4 inhibition influencing retrieval processes. The memory improvement after roflumilast inhibition in the scopolamine-induced memory deficit is in agreement with previous findings with rolipram [16]. Muscarinic receptors are crucially important for memory acquisition $[59,60]$ and it is assumed that scopolamine induces an acquisition deficit. The mechanism of action behind the attenuation of the cholinergic memory deficit is likely related to the presynaptic release of neurotransmitters including acetylcholine which might be mediated by increased levels of cAMP [61,62], as a result of inhibition of PDE4.

In conclusion, PDE4 inhibition is a promising pharmacological target for treatment of cognitive deficits. Roflumilast has a more optimal window for memory enhancement than rolipram since its emetic potential is more than 10 times lower than that of rolipram. Roflumilast in low doses, to further avoid possible emetic effects, can also be considered as a combination therapy with low doses of AChE-Is to avoid the latter's gastrointestinal effects. Considering the complexity of the PDE4 family with its many isoform specific subtypes, further research is needed to establish the diversity of effects on cognition, but also side effect profiles including emesis.

\section{Acknowledgement}

Takeda (Deerfield, USA) funded the combination therapy study and participated in its design.

\section{References}

[1] J.S. Silvestre, A.G. Fernández, J.M. Palacios, Preliminary evidence for an involvement of the cholinergic system in the sedative effects of rolipram in rats, Pharmacol. Biochem. Behav. 64 (1999) 1-5.

[2] C.H. Bailey, D. Bartsch, E.R. Kandel, Toward a molecular definition of long-term memory storage, Proc. Nat. Acad. Sci. U. S. A. 93 (1996) 13445

[3] M. Barad, R. Bourtchouladze, D.G. Winder, H. Golan, K.E. Rolipram, A type IV-specific phosphodiesterase inhibitor, facilitates the establishment of long-lasting long-term potentiation and improves memory, Proc. Nat. Acad. Sci. U. S. A. 95 (1998) 15020

[4] U. Frey, Y. Huang, E. Kandel, Effects of cAMP simulate a late stage of LTP in hippocampal CA1 neurons, Science 260 (1993) 1661-1664

[5] Y.F. Li, Y.F. Cheng, Y. Huang, M. Conti, S.P. Wilson, J.M. O’Donnell, et al., Phosphodiesterase-4D knock-out and RNA interference-mediated knock-down enhance memory and increase hippocampal neurogenesis via increased cAMP signaling, J. Neurosci. 31 (2011) 172-183.

[6] H.T. Zhang, Cyclic AMP-specific phosphodiesterase-4 as a target for the development of antidepressant drugs, Curr. Pharm. Des. 15 (2009) 1688-1698

[7] V. Dal Piaz, M.P. Giovannoni, Phosphodiesterase 4 inhibitors, structurally unrelated to rolipram, as promising agents for the treatment of asthma and other pathologies, Eur. J. Med. Chem. 35 (2000) 463-480.

[8] A. Martinez, C. Gil, cAMP-specific phosphodiesterase inhibitors: promising drugs for inflammatory and neurological diseases, Expert Opin. Ther. Patents 24 (2014) 1311-1321.

[9] D. Spina, PDE4 inhibitors: current status, Br. J. Pharmacol. 155 (2008) 308-315.

[10] A.B. Burgin, O.T. Magnusson, J. Singh, P. Witte, B.L. Staker, J.M. Bjornsson, et al., Design of phosphodiesterase 4D (PDE4D) allosteric modulators for enhancing cognition with improved safety, Nat. Biotechnol. 28 (2009) 63-70. 
[11] O.A.H. Reneerkens, K. Rutten, H.W.M. Steinbusch, A. Blokland, J. Prickaerts, Selective phosphodiesterase inhibitors: a promising target for cognition enhancement, Psychopharmacology 202 (2009) 419-443.

[12] N.N. Braun, T.J. Reutiman, S. Lee, T.D. Folsom, S.H. Fatemi, Expression of phosphodiesterase 4 is altered in the brains of subjects with autism, Neuroreport 18 (2007) 1841-1844.

[13] A. Ugarte, F. Gil-Bea, C. Garcia-Barroso, A. Cedazo-Minguez, M.J. Ramirez, R. Franco, et al., Decreased levels of cGMP in CSF are associated with cognitive decline and amyloid pathology in Alzheimer's disease, Neuropathol. Appl. Neurobiol. 41 (2015) 471-482.

[14] M.N. de Lima, J. Presti-Torres, V.A. Garcia, M.R. Guimaraes, F.S. Scalco, R. Roesler, et al., Amelioration of recognition memory impairment associated with iron loading or aging by the type 4-specific phosphodiesterase inhibitor rolipram in rats, Neuropharmacology 55 (2008) 788-792.

[15] C.S. McLachlan, M.L. Chen, C.N. Lynex, D.L. Goh, S. Brenner, S.K. Tay, Changes in PDE4D isoforms in the hippocampus of a patient with advanced Alzheime disease, Arch. Neurol. 64 (2007) 456-457.

[16] K. Rutten, J. Prickaerts, A. Blokland, Rolipram reverses scopolamine-induced and time-dependent memory deficits in object recognition by different mechanisms of action, Neurobiol. Learn. Mem. 85 (2006) 132-138.

[17] R.T. Hansen 3rd, H.T. Zhang, Phosphodiesterase-4 modulation as a potential therapeutic for cognitive loss in pathological and non-pathological aging: possibilities and pitfalls, Curr. Pharm. Des. 21 (2015) 291-302.

[18] P.R. Heckman, A. Blokland, J. Ramaekers, J. Prickaerts, PDE and cognitive processing: beyond the memory domain, Neurobiol. Learn. Mem. 119 (2015) $108-122$.

[19] W. Richter, F.S. Menniti, H.T. Zhang, M. Conti, PDE4 as a target for cognition enhancement, Expert Opin. Ther. Targets 17 (2013) 1011-1027.

[20] M.E. Bach, M. Barad, H. Son, M. Zhuo, Y.F. Lu, R. Shih, et al., Age-related defects in spatial memory are correlated with defects in the late phase of hippocampal long-term potentiation in vitro and are attenuated by drugs that enhance the cAMP signaling pathway, Proc. Natl. Acad. Sci. U. S. A. 96 (1999) 5280-5285.

[21] B. Gong, O.V. Vitolo, F. Trinchese, S. Liu, M. Shelanski, O. Arancio, Persistent improvement in synaptic and cognitive functions in an Alzheimer mouse model after rolipram treatment, J. Clin. Investig. 114 (2004) 1624-1634.

[22] K. Rutten, J.L. Basile, J. Prickaerts, A. Blokland, J.A. Vivian, Selective PDE inhibitors rolipram and sildenafil improve object retrieval performance in adult cynomolgus macaques, Psychopharmacology (Berl.) 196 (2008) 643-648.

[23] J.S. Sutcliffe, V. Beaumont, J.M. Watson, C.S. Chew, M. Beconi, D.M. Hutcheson, et al., Efficacy of selective PDE4D negative allosteric modulators in the object retrieval task in female cynomolgus monkeys (Macaca fascicularis), PLoS One 9 (2014) e102449.

[24] M. Gallant, R. Aspiotis, S. Day, R. Dias, D. Dube, L. Dube, et al., Discovery of MK-0952, a selective PDE4 inhibitor for the treatment of long-term memory loss and mild cognitive impairment, Bioorg. Med. Chem. Lett. 20 (2010) 6387-6393.

[25] V. Girod, Nausea and emesis models for the safety evaluation of PDE4 inhibitors, J. Pharmacol. Toxicol. Methods 62 (2010) e13-e14.

[26] G. Hebenstreit, K. Fellerer, K. Fichte, G. Fischer, Rolipram in major depressive disorder: results of a double-blind comparative study with imipramine, Pharmacopsychiatry 22 (4) (1989) 156-160.

[27] M. Puhan, Phosphodiesterase 4 inhibitors for chronic obstructive pulmonary disease. The Cochrane database of systematic reviews. 2011: ED000028.

[28] K.F. Rabe, E.D. Bateman, D. O’Donnell, S. Witte, T.D. Bethke, Roflumilast-an oral anti-inflammatory treatment for chronic obstructive pulmonary disease: a randomised controlled trial, Lancet 366 (2005) 563-571.

[29] J. Chong, P. Poole, B. Leung, P.N. Black, Phosphodiesterase 4 inhibitors for chronic obstructive pulmonary disease, Cochrane Database Syst. Rev. 5 (2011).

[30] J. Izquierdo, J. Aparicio, Roflumilast for COPD, Drugs Today (Barcelona, Spain: 1998) 46 (2010) 823.

[31] D. Claveau, S.L. Chen, S. O’Keefe, D.M. Zaller, A. Styhler, S. Liu, et al. Preferential inhibition of T helper 1 , but not T helper 2, cytokines in vitro by L-826,141 [4-[2-(3,4-bisdifluromethoxyphenyl)-2-[4-(1,1,1,3,3,3-hexafluoro2-hydroxypropan-2-yl)-phenyl]-ethyl]3-methylpyridine-1-oxide], a potent and selective phosphodiesterase 4 inhibitor, J. Pharmacol. Exp. Ther. 310 (2004) 752-760.

[32] A. Robichaud, C. Savoie, P. Stamatiou, N. Lachance, P. Jolicoeur, R. Rasori, et al. Assessing the emetic potential of PDE4 inhibitors in rats, Br. J. Pharmacol. 135 (2002) 113-118

[33] A. Robichaud, P.B. Stamatiou, S.L.C. Jin, N. Lachance, D. MacDonald, F. Laliberté, et al., Deletion of phosphodiesterase 4D in mice shortens alpha 2 -adrenoceptor-mediated anesthesia, a behavioral correlate of emesis, J. Clin. Invest. 110 (2002) 1045-1052.

[34] M.E. Gurney, E.C. D’Amato, A.B. Burgin, Phosphodiesterase-4 (PDE4) molecular pharmacology and Alzheimer's disease, Neurother.: J. Am. Soc. Exp. Neurother. 12 (2015) 49-56.

[35] O. Bruno, E. Fedele, J. Prickaerts, L. Parker, E. Canepa, C. Brullo, et al., GEBR-7b, a novel PDE4D selective inhibitor that improves memory in rodents at non-emetic doses, Br. J. Pharmacol. 164 (8) (2011) 2054-2063.

[36] R. Ricciarelli, E. Fedele, Phosphodiesterase 4D: an enzyme to remember, Br. J. Pharmacol. 172 (2015) 4785-4789.

[37] K. Rutten, E.L. Van Donkelaar, L. Ferrington, A. Blokland, E. Bollen, H.W. Steinbusch, et al., Phosphodiesterase inhibitors enhance object memory independent of cerebral blood flow and glucose utilization in rats, Neuropsychopharmacology 34 (2009) 1914-1925

[38] A. Ennaceur, J. Delacour, A new one-trial test for neurobiological studies of memory in rats. 1: behavioral data, Behav. Brain Res. 31 (1988) 47-59.

[39] E. Loveman, C. Green, J. Kirby, A. Takeda, J. Picot, E. Payne, et al., The Clinical and Cost-effectiveness of Donepezil, Rivastigmine Galantamine and Memantine for Alzheimer's Disease, Gray Publishing, 2006.

[40] K. Rutten, J. Prickaerts, M. Hendrix, F.J. van der Staay, A. Sik, A. Blokland, Time-dependent involvement of cAMP and cGMP in consolidation of object memory: studies using selective phosphodiesterase type 2, 4 and 5 inhibitors, Eur. J. Pharmacol. 558 (2007) 107-112.

[41] J. Prickaerts, N.P. van Goethem, R. Chesworth, G. Shapiro, F.G. Boess, C. Methfessel, et al., EVP-6124, a novel and selective alpha7 nicotinic acetylcholine receptor partial agonist, improves memory performance by potentiating the acetylcholine response of alpha7 nicotinic acetylcholine receptors, Neuropharmacology 62 (2012) 1099-1110.

[42] T. Vanmierlo, K. Rutten, J. Dederen, V.W. Bloks, L.C. van Vark-van der Zee, F. Kuipers, et al., Liver $\mathrm{X}$ receptor activation restores memory in aged AD mice without reducing amyloid, Neurobiol. Aging 32 (2011) 1262-1272.

[43] S. Akkerman, A. Blokland, O. Reneerkens, N.P. van Goethem, E. Bollen, H.J. Gijselaers, et al., Object recognition testing: methodological considerations on exploration and discrimination measures, Behav, Brain Res. 232 (2012) 335-347.

[44] F. Dellu, A. Contarino, H. Simon, G.F. Koob, L.H. Gold, Genetic differences in response to novelty and spatial memory using a two-trial recognition task in mice, Neurobiol. Learn. Mem. 73 (2000) 31-48.

[45] A.S. Sierksma, J. Prickaerts, L. Chouliaras, S. Rostamian, L. Delbroek, B.P. Rutten, et al., Behavioral and neurobiological effects of prenatal stress exposure in male and female APPswe/PS1dE9 mice, Neurobiol. Aging 34 (2013) 319-337.

[46] O. Bruno, E. Fedele, J. Prickaerts, L.A. Parker, E. Canepa, C. Brullo, et al., GEBR-7b, a novel PDE4D selective inhibitor that improves memory in rodents at non-emetic doses, Br. J. Pharmacol. 164 (2011) 2054-2063.

[47] S.G. Jabaris, H. Sumathy, R.S. Kumar, S. Narayanan, S. Thanikachalam, C.S. Babu, Effects of rolipram and roflumilast, phosphodiesterase-4 inhibitors, on hypertension-induced defects in memory function in rats, Eur. J. Pharmacol. 746 (2015) 138-147.

[48] M. Peters, M. Bletsch, J. Stanley, D. Wheeler, R. Scott, T. Tully, The PDE4 inhibitor HT-0712 improves hippocampus-dependent memory in aged mice, Neuropsychopharmacology 39 (2014) 2938-2948.

[49] A. Hatzelmann, E.J. Morcillo, G. Lungarella, S. Adnot, S. Sanjar, R. Beume, et al., The preclinical pharmacology of roflumilast-a selective, oral phosphodiesterase 4 inhibitor in development for chronic obstructive pulmonary disease, Pulm. Pharmacol. Ther. 23 (2010) 235-256.

[50] J. Birks, L. Flicker, Donepezil for mild cognitive impairment. The Cochrane database of systematic reviews. 2006:CD006104.

[51] S.A. Hitchcock, L.D. Pennington, Structure-brain exposure relationships, J. Med. Chem. 49 (2006) 7559-7583.

[52] Y.F. Li, Y.F. Cheng, Y. Huang, M. Conti, S.P. Wilson, J.M. O’Donnell, et al. Phosphodiesterase-4D knock-out and RNA interference-mediated knock-down enhance memory and increase hippocampal neurogenesis via increased cAMP signaling, J. Neurosci. 31 (2011) 172-183.

[53] W. Krause, G. Kuhne, Pharmacokinetics of rolipram in the rhesus and cynomolgus monkeys, the rat and the rabbit: studies on species differences, Xenobiotica 18 (1988) 561-571.

[54] M. Fujita, S.S. Zoghbi, M.S. Crescenzo, J. Hong, J.L. Musachio, J.Q. Lu, et al., Quantification of brain phosphodiesterase 4 in rat with (R)-[11C]Rolipram-PET, NeuroImage 26 (2005) 1201-1210.

[55] C.M. Lourenco, S. Houle, A.A. Wilson, J.N. DaSilva, Characterization of r-[11C]rolipram for PET imaging of phosphodieterase-4: in vivo binding, metabolism, and dosimetry studies in rats, Nucl. Med. Biol. 28 (2001) 347-358

[56] Q. Guo, M. Brady, R.N. Gunn, A biomathematical modeling approach to centra nervous system radioligand discovery and development journal of nuclear medicine: official publication, Soc. Nucl. Med. 50 (2009) 1715-1723.

[57] M.S. Barnette, M. Grous, L.B. Cieslinski, M. Burman, S.B. Christensen, T.J. Torphy, Inhibitors of phosphodiesterase IV (PDE IV) increase acid secretion in rabbit isolated gastric glands: correlation between function and interaction with a high-affinity rolipram binding site, J. Pharmacol. Exp. Ther. 273 (1995) 1396-1402.

[58] E. Bollen, D. Puzzo, K. Rutten, L. Privitera, J. De Vry, T. Vanmierlo, et al. Improved long-term memory via enhancing cGMP-PKG signaling requires cAMP-PKA signaling, Neuropsychopharmacology 39 (2014) 2497-2505.

[59] F.J. Gil-Bea, M. Solas, L. Mateos, B. Winblad, M.J. Ramirez, A. Cedazo-Minguez, Cholinergic hypofunction impairs memory acquisition possibly through hippocampal Arc and BDNF downregulation, Hippocampus 21 (2011) 999-1009.

[60] L. Robinson, B. Platt, G. Riedel, Involvement of the cholinergic system in conditioning and perceptual memory, Behav. Brain Res. 221 (2011) 443-465.

[61] T. Imanishi, A. Sawa, Y. Ichimaru, M. Miyashiro, S. Kato, T. Yamamoto, et al., Ameliorating effects of rolipram on experimentally induced impairments of learning and memory in rodents, Eur. J. Pharmacol. 321 (1997) 273-278.

[62] A.N. Schoffelmeer, G. Wardeh, A.H. Mulder, Cyclic AMP facilitates the electrically evoked release of radiolabelled noradrenaline, dopamine and 5-hydroxytryptamine from rat brain slices, Naunyn-Schmiedeberg's Arch. Pharmacol. 330 (1985) 74-76. 